\title{
AS POLÍTICAS EDUCACIONAIS E A FORMAÇÃO INICIAL DE PROFESSORES: A DIDÁTICA NA RESOLUÇÃO 002/2015
}

\author{
EDUCATIONAL POLICIES AND INITIAL TEACHER TRAINING: DIDACTICS IN \\ RESOLUTION 002/2015
}

POLÍTICAS EDUCACIONALES Y LA FORMACIÓN INICIAL DE PROFESORES:

LA DIDÁCTICA EN LA RESOLUCIÓN 002/2015

Marcos Gehrke ${ }^{1}$

Juliana Domit Mallat ${ }^{2}$

${ }^{1}$ Doutor em Educação pela UFPR. Docente do Programa de Pós-Graduação em Educação da Universidade Estadual do Centro-Oeste (UNICENTRO), Guarapuava, PR, Brasil.

2Mestre em Educação pela UNICENTRO. Docente do Curso de Pedagogia da Universidade Estadual do Centro-Oeste (UNICENTRO), Guarapuava, PR, Brasil.

Resumo: Apresenta dados sobre a Formação Inicial de Professores na trajetória histórica das políticas educacionais, com enfoque na década de 1990 até a atualidade. Situa a mesma como uma questão atual nos diferentes tempos históricos e, nesse contexto, marca os avanços e os retrocessos na conquista do direito; ampliação do tempo em contraponto à insistência de um aligeiramento na formação; disputas entre o público e o privado no atendimento; um currículo sempre em disputa. Analisa as políticas educacionais a partir da década de 1990, com enfoque na formação inicial de professores, destacando a importância da Didática no marco teórico-legal para a reestruturação dos cursos de licenciatura nas IEs, provocado pela Resolução 02/2015 (BRASIL, 2015) em voga no Brasil. Faz análise documental desde a Lei de Diretrizes e Bases (BRASIL, 1996), as Diretrizes Nacionais para a Formação Inicial de Professores (BRASIL, 2002; 2015), e estudos bibliográficos a partir da categoria "políticas educacionais" (GATTI, 2009; 2010); o campo da Didática e a formação de professores (LIBÂNEO, 1985, MARINS; PIMENTA, 2015, MARTINS \& ROMANOWSKI 2015; VEIGA 2012). Destaca que a Resolução 02/2015, na atualidade da política de formação de professores, expressa a contradição e deveria impulsionar um debate mais amplo sobre a crise na formação de professores. Defende que o campo da didática é indispensável à formação inicial de professores, sobretudo, a partir da necessidade de ensinar as origens, a história e a epistemologia das diferentes áreas de formação, superando a premissa de solucionar o divórcio entre as necessidades atuais da escola de educação básica e a formação promovida nos âmbitos do ensino superior. Palavras-chave: Formação Inicial de Professores; Políticas Educacionais; Didática.

Abstract: This article presents research data on Initial Teacher Training, in the historical trajectory of educational policies, focusing on the period from the 1990s up to the present time. It situates the topic as a current issue in the different historical periods, and in this context, marks the advances and setbacks in the conquest of the right; extension of time in counterpoint to the insistence on a lighter training; disputes between public and private care; and a curriculum constantly in dispute. It analyzes educational policies from the 1990s, focusing on the initial training of teachers, highlighting the 
importance of didactics in the theoretical-legal framework for the restructuring of undergraduate courses in educational institutions, prompted by resolution 02/2015 (BRAZIL, 2015) in vogue in Brazil. It provides documentary analysis from the Law of Guidelines and Bases [Lei de Diretrizes e Bases] (BRASIL, 1996), the National Guidelines for the Initial Training of Teachers [Diretrizes Nacionais para a Formação Inicial de Professores] (BRASIL, 2002, 2015), and bibliographical studies based on the category "educational policies" (GATTI, 2009; the field of didactics and teacher training (LIBANEO, 1985; MARINS, PIMENTA, 2015; MARTINS \& ROMANOWSKI, 2015; VEIGA, 2012). It emphasizes that resolution 02/2015, in the current teacher training policy, expresses the contradiction and should stimulate a broader debate on the crisis in teacher training. It argues that the field of didactics is indispensable to the initial training of teachers, especially in view of the need to teach the origins, history and epistemology of the different areas of training, overcoming the premise of resolving the separation between the current needs of basic education schools and the training promoted in higher education. Keywords: Initial Teacher Training; Educational Policies; Didactics.

Resumen: Presenta datos de investigación sobre la Formación Inicial de Profesores, en la trayectoria histórica de las políticas educacionales con el enfoque en la década de 1990 hasta la actualidad. La sitúa como una cuestión actual en los diferentes tiempos históricos y en ese contexto marca los avances y retrocesos en la conquista del derecho; ampliación del tiempo en contrapunto la insistencia de un aligeramiento en la formación; disputas entre el público y el privado en el atendimiento; un currículum siempre en disputa. Analiza las políticas educacionales a partir de la década de 1990 con enfoque en la formación inicial de profesores, destacando la importancia de la Didáctica en el marco teórico legal para la reestructuración de los cursos de licenciatura en las IES, provocado por la resolución 02/2015 (BRASIL, 2015) vigente en Brasil. Hace análisis documental desde la Ley de Directrices y Bases (BRASIL, 1996), las Directrices Nacionales para la Formación Inicial de Profesores (BRASIL, 2002; 2015), y estudios bibliográficos desde la categoría "políticas educacionales" (GATTI, 2009; 2010); el campo de la Didáctica y la formación de profesores (LIBÂNEO, 1985, MARINS, PIMENTA, 2015, MARTINS \& ROMANOWSKI, 2015; VEIGA 2012). Destaca que la resolución 02/2015, en la actualidad de la política de formación de profesores, expresan la contradicción y deberían impulsar un debate más amplio sobre la crisis en la formación de profesores. Defiende que el campo de la didáctica es indispensable a la formación inicial de profesores, sobre todo a partir de la necesidad de enseñar los orígenes, la historia y epistemología de las diferentes áreas de formación, superando la premisa de solucionar el divorcio entre las necesidades actuales de la escuela de enseñanza básica y la formación promovida en los ámbitos de enseñanza superior. Palabras clave: Formación Inicial de Profesores; Políticas Educacionales; Didáctica.

INTRODUÇÃO

Apresentamos dados sobre a formação inicial de professores na trajetória histórica das políticas educacionais com enfoque na década de 1990. A pesquisa na formação inicial de professores, no Brasil, é uma questão atual nos diferentes tempos históricos. Nela, identificamos avanços e retrocessos na conquista do direito; na ampliação do tempo em contraponto à insistência de um aligeiramento na formação; nas disputas entre o público e o privado no atendimento; e num currículo de formação sustentado no ensino por competências (BRASIL, 2002), entre tantos outros aspectos de ordem política e conjuntural, todos tensionados na Resolução 002/2015 (BRASIL, 2015).

Diante dessa conjuntura, questionamos a formação inicial de professores no marco teórico-legal e o lugar da didática nesse cenário. Logo, demarcamos que a concepção de didática assumida na diretriz indica uma aproximação entre o ensino superior e a educação 
básica, valorizando à docência como um processo pedagógico e a relação teoria e prática, como componente curricular que deve permear todo o processo formativo (BRASIL, 2015).

Como objetivo, propomos a análise das políticas educacionais a partir da década de 1990, com enfoque na formação inicial de professores, destacando a importância da Didática no marco teórico-legal para a reestruturação dos cursos de licenciatura nas IEs, provocado pela Resolução 02/2015 (BRASIL, 2015) em voga no Brasil.

A investigação desenvolvida é de natureza qualitativa, que segundo Lüdke e André (1986, p. 13), " [...] envolve a obtenção de dados descritivos, obtidos no contato direto do pesquisador com a situação estudada, enfatiza mais o processo do que o produto". Nesse sentido, empregamos a análise documental e o estudo bibliográfico na produção dos dados. Como estudo documental, levantamos as políticas educacionais desde a Lei de Diretrizes e Bases (BRASIL, 1996), até as Diretrizes Nacionais para a Formação Inicial de Professores (BRASIL, 2002; 2015). No estudo bibliográfico, buscamos o referencial teórico a partir da categoria "políticas educacionais" (GATTI, 2009; 2010) e para compreender o campo da Didática e a formação de professores (LIBÂNEO 1985, MARIN; PIMENTA 2015, MARTINS \& ROMANOWSKI 2015; VEIGA 2012).

Na primeira seção, apresentamos um panorama das políticas educacionais voltadas à formação inicial de professores a partir da década de 1990, posteriormente, o campo da Didática na formação de professores e, na última seção, pautamos nossa análise na Didática a partir da Resolução 02/2015 (BRASIL, 2015). Por fim, nas considerações finais, retomamos, de maneira objetiva, os propósitos aqui expressos, apresentando, a seguir, as referências.

\section{Políticas Educacionais e formação inicial de PROFESSORES}

Essa pesquisa é marcada por um conjunto de fatos que se consolidam num espaço contraditório, em razão da conjuntura da formação de professores na agenda política. A partir dos anos 1990, após os acordos com organismos internacionais, a Conferência Mundial de Educação para Todos, a promulgação da Lei de Diretrizes e Bases da Educação - LDB 9.9394/96 (BRASIL, 1996) e o fortalecimento dos financiamentos junto ao Banco Mundial, entre outros. Vemos, mais uma vez, um quadro em que a formação de professores é palco de disputa (FREITAS, 1999).

$\mathrm{Na}$ conjuntura dos anos 1990, definiram-se novos rumos à educação brasileira, sustentados no capitalismo, cujo projeto educacional baseava-se numa economia de mercado e no acesso cada vez maior às instituições privadas, especialmente, em nível superior. Em virtude disso, fortaleceram-se dois importantes protagonistas na educação brasileira: o Banco Mundial (LEHER, 1999), que já estava presente desde a década de 1950 na agenda política e financeira brasileira e a LDB 9394/1996 (BRASIL, 1996).

No cerne da ideologia do capitalismo e a mundialização do capital, as diretrizes do Banco Mundial, anunciadas por Leher (1999) como "Ministério Mundial da Educação", materializaram a dimensão instrumental da educação, o aprender a aprender e aprender a fazer, servindo à dinâmica do capital. Os acordos internacionais garantiram a consolidação do poder neoliberal (LEHER, 1999), subscrevendo estratégias aos países periféricos, confirmando-se, principalmente, 
a partir da Conferência Mundial de Educação para Todos (UNESCO, 1990), que resultou em um acordo entre 155 países, com o objetivo de assegurar uma educação básica de qualidade. Sustentando-se na parceria público/privado (VILLAS, 2014), deu continuidade a um processo iniciado amplamente na ditadura militar, caracterizando-se como um:

[...] marco a partir do qual os nove países com a maior taxa de analfabetismo do mundo (Bangladesch, Brasil, China, Egito, Índia, Indonésia, México, Nigéria e Paquistão), conhecidos como 'E9', foram levados a desencadear ações para a consolidação dos princípios acordados na Declaração de Jomtien. Seus governos comprometeram-se a impulsionar políticas educativas articuladas a partir do fórum consultivo internacional para a 'Educação para Todos' (Education for All -EFA) coordenado pela UNESCO que, ao logo da década de 1990, realizou reuniões regionais e globais de natureza avaliativa. (EVANGELISTA; MORAES; SHIROMA, 2007, p. 48).

As ideias efervescentes da Conferência Mundial de Educação para Todos, documento elaborado em 1993 pelo Ministério da Educação (MEC), estabeleceram as metas para serem cumpridas num prazo de 10 anos, sendo consideradas um conjunto de diretrizes políticas voltadas para a recuperação da escola fundamental no país e que, segundo Evangelista, Moraes e Shiroma, (2007, p.52) "[...] traçava as metas locais a partir do acordo firmado em Jomtien e acenava aos organismos multilaterais que o projeto educacional por eles prescrito seria aqui implantado".

Para o contexto escolar, o Banco Mundial visava atrelar metas educacionais a metas econômicas, por meio de um discurso de redução da ignorância e da pobreza. Segundo Libâneo (2008), a escola é vista como instituição que atende às necessidades imediatas de sobrevivência, ritmos e interesses individuais, partindo de conteúdos mínimos para a formação de competências e habilidades, num total esvaziamento de conteúdos científicos, reflexivos e políticos. O que influenciou na constituição das políticas de formação inicial de professores, conforme explicam Marin e Pimenta (2015), que concordam com Brzezinski (2002, p. 83):

O que é evidente nas atuais políticas educacionais de formação de professores é que, apesar de a educação básica do brasileiro ter tomado um lugar central no discurso oficial e no dos detentores do capital, as ações do governo são de desvalorização do papel social e cultural dos profissionais da educação, e de desmantelamento das estruturas das instituições superiores responsáveis pela formação de professores.

Nesse sentido, a educação preconizada pelo governo caminhou, juntamente, com os acordos estabelecidos nos anos 1990, resultando na promulgação da LDB 9394/1996 (BRASIL, 1996), contribuindo para a privatização do ensino e para o aumento desenfreado das instituições de educação a distância, especialmente, no ensino superior. Assim, Brasil (1996, p.43) definiu que "A educação superior será ministrada em instituições de ensino superior, públicas ou privadas, com variados graus de abrangência ou especialização", privilegiando a formação aligeirada, frágil na teoria e na prática (MARIN; PIMENTA, 2015).

Com a democratização do ensino, pautada na hegemonia do projeto neoliberal (VEIGA, 2012), a LDB 9394/1996 (BRASIL, 1996) definiu por meio do art. 62 como exercício mínimo do magistério "[...] professores habilitados em nível médio ou superior para a docência na educação infantil e nos ensinos fundamental e médio" (BRASIL, 1996), formação essa a ser ofertada em Institutos Superiores de Educação, em cursos preferencialmente presenciais, definindo que tais institutos manterão:

I - cursos formadores de profissionais para a educação básica, inclusive o curso normal superior, destinado à formação de docentes para a educação infantil e para as primeiras séries do ensino fundamental; 
II - programas de formação pedagógica para portadores de diplomas de educação superior que queiram se dedicar à educação básica;

III - programas de educação continuada para os profissionais de educação dos diversos níveis. (BRASIL, 1996, p. 22).

A leitura dos artigos permite compreendermos que a formação de professores sofreu fortes impactos, uma vez que foram criadas e expandidas instituições privadas de Ensino Superior, constituindo-se como um desmonte da formação inicial de professores a partir das tendências neoliberais (MELO; URBANETZ, 2008). Em síntese, a formação de um professor "prático" (FREITAS, 1995), ou seja, "[...] quem sabe fazer, sabe ensinar" (MARIN; PIMENTA, 2015, p. 126).

O projeto de formação proposto decorre da necessidade do modelo produtivo que exige do trabalhador, especialmente, o domínio das novas tecnologias, "[...] o aprender a pensar, a resolver problemas novos e imprevistos; precisa ter uma formação polivalente. Uma formação que lhe permita realizar tarefas diversas e, além disso, a transitar com mais facilidade de um emprego a outro" (TONET, 2016, p 14).

O cenário de educação descrito é formulado e legislado em forma de Diretrizes Curriculares Nacionais para a Formação de Professores (DCNs) (BRASIL,2002), e segundo Romanowski (2007), definindo a organização dos cursos de licenciatura, Pedagogia e Normal Superior. As DCNs (BRASIL, 2002) passam a ser o elemento legal e central para a implementação da política educacional para a formação inicial de professores.

Os autores que analisam a legislação do período (GATTI, 2010; SCHIBE, 2013; BRZEZINSKI, 2002) concordam que a concepção de formação de professores recai no ensino por competências, definindo que essa deve considerar o "[...] conjunto das competências necessárias à atuação profissional" (BRASIL, 2002, p.2). Para isso, adotaram-se as competências como norteadoras da proposta pedagógica, especialmente, do currículo, avaliação e gestão escolar.

As DCNs aprovadas levaram as instituições de ensino de formação de professores a adequar seus projetos políticos pedagógicos e programas das disciplinas, trazendo como marca central o ensino por competência e o estágio como formação prática dos cursos, valorizando a aproximação dos estudantes da educação básica somente na disciplina de estágio, prevalecendo a formação específica das disciplinas com pouco espaço para a formação pedagógica (GATTI, 2010), adentrando no século XXI, repetindo a formação consolidada no século anterior.

Essa concepção formativa continua em vigor no contexto das instituições formadoras e começa a ser repensada a partir de julho de 2015, quando entra para o cenário educacional uma nova proposição, que anuncia rupturas com o paradigma da formação em vigor. A Resolução 002/2015 anuncia Diretrizes Curriculares Nacionais para a Formação dos Profissionais do Magistério para a Educação Básica (BRASIL, 2015), que compreende formação inicial em nível superior: "Cursos de graduação de licenciatura; Cursos de formação pedagógica para graduados não licenciados e Cursos de segunda licenciatura" (BRASIL, 2015, p.1).

A Resolução 02/2015 (BRASIL, 2015) apresenta como concepção de educação um processo emancipatório e permanente, que reconhece a especificidade do trabalho docente, conduzido pela práxis, na articulação entre teoria e prática, a partir da realidade dos ambientes das instituições educativas da educação básica e da profissão (BRASIL, 2015). 
Como materialização dessa proposta, propõe à formação inicial uma Base Nacional Comum Curricular assentada nos seguintes núcleos:

I - Núcleo de estudos de formação geral, das áreas específicas e interdisciplinares e do campo educacional, seus fundamentos e metodologias e das diversas realidades educacionais, articulando princípios e concepções, respeito a diversidade cultural e social, conhecimento multidimensional e interdisciplinar, pesquisas e estudos da legislação educacional e seus fundamentos;

II - Núcleo de aprofundamento e diversificação de estudos das áreas de atuação profissional incluindo os conteúdos específicos e pedagógicos e a pesquisa priorizada pelo projeto pedagógico da instituição, abordando diferentes campos do conhecimento acerca do currículo, de aspectos pedagógicos, filosóficos, psicológicos entre outros;

III - Núcleo de estudos integradores para enriquecimento curricular, compreendendo a participação em seminários, atividades práticas articuladas, projetos, monitoria e extensão, entre outros. (BRASIL, 2015, p.9).

Como norteadores dessa Base Nacional Comum, alguns princípios foram definidos, como "[...] sólida formação teórica e interdisciplinar; unidade teoria-prática; trabalho coletivo e interdisciplinar; compromisso social e valorização do profissional da educação; gestão democrática; avaliação e regulação dos cursos de formação" (BRASIL, 2015, p.2).

Esses princípios devem, ainda, assegurar a diversidade das especificidades dos campos de atuação dos profissionais do magistério, como a educação indígena, quilombola, especial e do campo, implicando novos horizontes às instituições formativas, reconhecendo as especificidades da formação.

\section{A Formação Inicial de Professores e o Campo da Didática}

A questão da formação inicial de professores vem ganhando notoriedade, em especial nas duas últimas décadas, sejam nas discussões acadêmicas, na pesquisa educacional ou nas políticas educacionais. Autores como Libâneo (1991), Martins e Romanowski (2015), Veiga (1994), entre outros, têm apontado uma lacuna entre a formação inicial e a prática profissional na educação básica, sendo um dos fatores relevantes para isso a falta de formação pedagógica nos cursos de licenciatura. Gatti (2009) anuncia, em sua pesquisa acerca da formação inicial de professores nos cursos de Licenciatura que, em média, apenas $10 \%$ da formação nesses cursos destina-se à formação pedagógica, ou seja, aos conteúdos da docência.

A formação inicial de professores é definida, a partir de Marcelo (1999, p.26), como:

[...] a área de conhecimentos, investigação e de propostas teóricas e práticas que, no âmbito da didática e da organização escolar, estuda os processos através dos quais os professores-em formação ou em exercício-se implicam individualmente ou em equipe, em experiências de aprendizagem através das quais adquirem ou melhoram os seus conhecimentos, competências e disposições, e que lhes permitem intervir profissionalmente no desenvolvimento do seu ensino, do currículo e da escola, com o objetivo de melhorar a qualidade da educação que os estudantes recebem.

Gatti (2010) complementa Marcelo (1999) e afirma que as licenciaturas são cursos que, pela legislação, têm o objetivo de formar professores para a educação básica: educação infantil (creche e pré-escola); ensino fundamental; ensino médio; ensino profissionalizante; educação de jovens e adultos e educação especial. Dessa forma, independente da modalidade de educação em que o estudante atuará, todos os cursos de licenciatura formam professores e têm como um de seus principais objetivos a formação pedagógica, anunciada por Marcelo (1999, p.5) como responsável pelos "conhecimentos e habilidades que os professores possuem e que 
estão relacionados com o ensino, com a aprendizagem, com os estudantes; assim como sobre os princípios gerais do ensino [...]". Romanowski (2016) compreende-os como conhecimentos basilares da formação inicial, constituindo-se sob o campo teórico e prático, estruturantes da formação docente (ROLDÃO, 2007).

A partir do referencial estudado, compreendemos a Didática como a principal disciplina responsável pela formação pedagógica dos futuros professores, uma vez que ela tem o dever de clarificar o papel político da educação, auxiliando na politização do futuro professor, "[...] comprometida com seu povo e com o seu tempo" (VEIGA, 1994, p. 69), materializando-se sob aspectos teóricos e práticos que investiga, reflete e recria o processo de ensino aprendizagem em todas as etapas da educação básica, expressando a organização da escola, do ensino, do conhecimento e da sociedade (VEIGA, 2012).

Assim, a Didática vai muito além de uma disciplina, está presente em todo o contexto formativo dos professores, relacionando-se, diretamente, com as demais áreas do conhecimento e, segundo Saviani (2008), englobando diferentes esferas científicas (teoria da educação, teoria do conhecimento, psicologia, sociologia, dentre outros), estudando dois polos de uma realidade complexa, alicerçada na prática social.

Nesse sentido, o campo da Didática na formação inicial de professores sustenta-se sob as disciplinas de Didática Geral e Didática Específica, tendo como um de seus objetivos solucionar o divórcio entre as necessidades atuais da escola de educação básica e a formação promovida nos âmbitos do ensino superior (PIMENTA, 2012). Para isso, estuda o processo de ensinar e aprender a partir de origens, história e epistemologia das diferentes áreas de formação, ocupando-se do processo de ensino aprendizagem específico de uma disciplina (LIBÂNEO, 2013) e das mediações entre a teoria educativa e a prática educativa escolar, uma vez que a prática docente precisa da teoria, que se funda na prática, refere-se à prática, mas é teoria.

Portanto, a didática como área de conhecimento, seja na Didática Geral ou nas específicas, tem um papel fundamental nos cursos de licenciatura, constituindo-se como uma disciplina que orienta a prática e sistematiza saberes pedagógicos que serão levados às salas de aula. Constitui as ações docentes permeando o processo de ensino aprendizagem, apontando para uma formação dotada de conhecimentos e competências específicas que diferenciam o professor de outros profissionais, tendo a docência como base de sua formação (BRZEZINSKI, 2002).

Nas décadas de 1980/1990, há no campo da formação de professores uma organização coletiva de educadores que discutiam a importância da formação de uma consciência crítica, socialização do conhecimento, democratização do ensino e a permanência da classe trabalhadora na escola (LIBÂNEO, 2013). As preocupações e as discussões fundamentaram, então, as propostas de uma pedagogia crítica, que definia a escola como uma instituição com o papel de socializar o saber, o conhecimento elaborado, a cultura erudita e não a cultura popular, denunciando o poder da hegemonia dominante e a perpetuação das desigualdades sociais (SAVIANI, 1984; LIMA et al., 2012).

A pedagogia crítica (SAVIANI, 1991) defende o compromisso com a democratização e a socialização do saber sistematizado, especialmente para a libertação das classes e de ações 
dialéticas entre a escola e a sociedade (MELO; URBANETZ, 2008). Nesse contexto, Saviani (1991) concebe o ensino por meio da prática social, caracterizando a didática como mediadora do polo teórico e prático, que não se reduz a conteúdos, mas se fundamenta nas relações e na contextualização dos saberes numa sociedade que está sempre em transformação.

A Didática assume, aqui, uma matriz epistemológica dialético-materialista, para a qual, segundo Oliveira (2011, p. 164), " [...] por meio do trabalho, o homem que é produto das práticas sociais das quais ele participa, estabelece relação com o mundo, que é uma relação concreta, determinada por múltiplos fatores em constante movimento[...]", envolvendo a historicidade e a intencionalidade do processo educativo.

As propostas para a Didática, a partir de Saviani (2009), expressam um novo cenário ao campo da Didática, cenário esse essencial às rupturas da didática instrumental, que passa a conceber e discutir com maior profundidade as relações sociopolíticas na educação. Entretanto, não rompem, ainda, com o ensino além da sala de aula (FREITAS, 1995), valorizando a educação escolar como um privilégio da escola. Nesse sentido, defendemos que a escola é um local de socialização, de vida e de trabalho, e que a educação é fundamental para a hominização (GHEDIN, 2012), decorrente de práticas que devem materializar-se em diferentes espaços e tempos.

Contraditoriamente a todas essas discussões, sob a perspectiva de ensino de uma Didática crítica à formação inicial de professores, as políticas educacionais da década de 1990 sustentamse nos princípios do neoliberalismo, como o controle, as avaliações externas, a desvalorização da formação pedagógica e a necessidade de uma formação aligeirada (VEIGA, 2012). Essa proposta de formação, anunciada pelas DCNs (BRASIL, 2002), resulta no modelo preconizado pelas políticas neoliberais, na concepção dos quatro pilares para a educação básica (VEIGA, 2012). Aprender a aprender, aprender a conviver, aprender a fazer e aprender a ser estão expressos no relatório de Jaques Delors, documento resultante da Conferência Mundial de Educação para Todos, que aponta orientações para a educação e o desenvolvimento do país. Assim, a Didática na formação inicial de professores passa a priorizar estratégias de ação, como o controle do tempo, a produtividade, a tecnologia, a fragmentação e o aprender a aprender, modelando comportamentos (MARTINS, 2012), de forma que aos estudantes é necessário "[...] dar respostas específicas definidas nos objetivos operacionais" (MARTINS, 2012, p. 92).

Nesse contexto, a formação de professores passa pela relativização do conhecimento e do esvaziamento teórico (LIBÂNEO, 2002), uma vez que prioriza as relações de sucesso dos indivíduos, pela ideologia da empregabilidade (DUARTE, 2004). Os fins educacionais são convertidos em meios para a materialização do ensino por competências, ofertado aos indivíduos por exigência do capital (DUARTE, 2004), expressando

[...] ausência de uma política de Estado que assuma sua responsabilidade pela formação inicial dos professores com a qualidade requerida pelo mundo contemporâneo. De outro, o pathos institucional revelado, entre outros indicadores, pela força de posicionamentos rigidamente estratificados em relação à natureza e ao valor do conhecimento científico e ao papel social da educação superior voltada a formar professores, colocando esta última tarefa em situação francamente subalterna àquela. É importante observar que tal posicionamento é consentâneo a posturas político-institucionais que privilegiam o trabalho acadêmico de investigação e produção do conhecimento, em detrimento do trabalho da docência. (SCHEIBE; BAZZO, p. 23, 2013). 
Ao anunciar a presença e a valorização das práticas de ensino nos cursos de licenciatura, identificamos as imposições do Banco Mundial e suas diretrizes para a formação de professores, que vem promovendo uma anemia teórica (MARIN; PIMENTA, 2015) e que ecoa o enfraquecimento da teoria pedagógica. Nessa perspectiva, a Didática Geral é retirada ou pouco relevante, uma vez que emerge do estudo de saberes sociológicos, psicológicos e históricos, restringindo seu "[...] papel de acolhimento e integração social dos estudantes, levando ao esvaziamento de suas funções em relação ao conhecimento e à aprendizagem" (MARIN; PIMENTA, 2015, p. 41).

Freitas (2005), Libâneo (2013), Saviani (2008) e Veiga (1994, 2012) definem a Didática como campo do conhecimento que privilegia a ação docente, considerando a relação pedagógica, as estratégias de aprendizagem e os caminhos didáticos investigativos, permeada por intencionalidades sociopolíticas e pedagógicas, numa ampla formação para a prática social, materializada em uma atuação efetiva essencial à formação de professores. Os mesmos autores defendem que tais conhecimentos pertencem à Didática Geral, mas que, além desta, há elementos indispensáveis à formação inicial de professores também nas didáticas específicas, que se constituem como conhecimentos didático-pedagógicos do conhecimento disciplinar, enfatizando a metodologia do seu ensino (LIBÂNEO, 2013).

Nesse cenário, há um dissenso nas ações projetadas nos currículos dos cursos de licenciatura e, o que há de concreto, é que isso se reproduz nos trabalhos em sala de aula de toda a educação básica, refletindo na escola pública e enfraquecendo a Didática como campo mais amplo da educação e da Pedagogia (LIBÂNEO, 2013). Isso decorre, segundo Gatti (2009), de alguns fatores como a falta de relevância nos cursos de licenciatura nas universidades brasileiras e das questões também apontadas por Martins e Romanowski (2015), de predominância dos conteúdos específicos sobre as disciplinas pedagógicas.

Nesse contexto, a formação dos profissionais do magistério se constitui como um campo de disputas de concepções políticas e curriculares e que, segundo Chauí (1994), necessita que a universidade se posicione ante a crise da racionalidade. Todavia, a Didática tem relação com essas questões, uma vez que ensino envolve enfrentamento, o que implica o repensar da dimensão epistemológica para esse campo na formação de professores (OLIVEIRA, 1992).

Na sequência, trazemos a Resolução 02/2015, que a nosso ver é um instrumento que materializa e expressa o campo de disputa na formação de professores, atualmente, no Brasil.

\section{A Resolução 02/2015 e o Campo da Didática}

O momento que circunstanciava a sociedade na homologação da Resolução 02/2015 é bem distinto do momento em que se foram publicadas as diretrizes ainda em vigor, DCNs 02/2001. É pertinente apontar que ocorreu um intervalo significativo de tempo entre uma e outra resolução e que esse período foi permeado por importantes documentos e debates, como o Plano Nacional de Educação e as discussões ocorridas no CONAE (2010-2014) (KASTELIJNS; DOMINGUES 2016). 
A conjuntura em que se apresenta à Resolução 02/2015 é frágil, uma vez que um governo a discutiu e a aprovou e, logo após a sua aprovação, esse governo foi retirado da presidência da república. Nesse cenário, há também a aprovação aligeirada de reformas e medidas que alteram, significativamente, a educação brasileira e os cursos de formação de professores, justificando o adiamento da aprovação do texto final da Resolução 02/2015.

Entre as medidas aprovadas pelo governo atual está a reforma do Ensino Médio, publicada sob a Medida Provisória n 746 de 2016 (BRASIL, 2016), num cenário de urgência, que encerra a discussão sobre o ensino médio, impondo a visão do Estado (FREITAS, 2016). De acordo com Frigotto (2016), declara o estrangulamento do acesso da classe trabalhadora à universidade, num projeto que põe fim à escola unitária e se definem duas escolas: a de pobres e a de ricos.

Na mesma lógica de reformas educacionais e políticas, o governo anuncia a Base Nacional Comum Curricular (BNCC), com a premissa de redução de desigualdades sociais, definindo linhas gerais ao processo de ensino e aprendizagem, propondo conteúdos e aprendizagens mínimas a todo ensino básico e transformando o currículo das escolas básicas a partir de áreas do conhecimento, compreendendo as áreas de Linguagens, Matemática, Ciências da Natureza e Ciências Humanas. As mudanças que vêm ocorrendo no âmbito da formação de professores, na sociedade atual, contribuem para reforçar o pensamento construído desde a colonização brasileira, de que a educação é necessária para instruir cidadãos a servir ao capital (FRIGOTTO, 2012), sob pressão esmagadora das políticas públicas, as quais atendem, especificamente, aos direitos privados.

Nessa disputa política, insere-se, também, a disputa pelo conhecimento e pelos currículos que definem a formação inicial de professores nas instituições de Ensino Superior, questão emblemática travada desde o início da formação de professores no Brasil. Todavia, denotam uma disputa interna nas universidades, seja por carga horária, por poder departamental e pela própria concepção de formação de professores (ROMANOWSKI; GISI; MARTINS, 2008). Nas instituições formadoras, consolidam-se, especialmente, na disputa dos cursos de Licenciatura, sob a questão historicamente travada entre a formação específica disciplinar da área do conhecimento versus a formação pedagógica (GATTI, 2010; MARTINS \& ROMANOWSKI, 2015; VEIGA, 2012).

Nesse contexto, justifica-se a ausência da Didática Geral (MARTINS \& ROMANOWSKI, 2015; VEIGA, 2012), uma vez que estuda o processo de ensino e aprendizagem sob uma perspectiva de compreensão da realidade. Gira em torno de um professor politicamente comprometido com a transformação social (MARTINS, 2012), buscando compreender a relação entre a prática escolar e a estrutura social mais ampla.

Parece-nos que o momento atual repete as mesmas questões políticas e educacionais dos anos 1990. De um lado um grupo de educadores apoiados numa perspectiva crítica de ensino, buscando romper com a educação do capital e, de outro, as políticas educacionais de mercado, valorizando a formação teórica e prática desvinculada de uma perspectiva social. Nesse sentido, cabe-nos refletir acerca das possibilidades de mudanças curriculares anunciadas pela Resolução 02/2015 e, principalmente, debatê-las amplamente nos fóruns de licenciatura, valorizando o que vem sendo amplamente desvalorizado, o campo da Didática, contudo da didática geral, crítica, na formação inicial de professores. 
Inicialmente, contribuindo para esta discussão, a Resolução 02/2015 propõe uma aproximação entre ensino superior e escolas de educação básica, discursando pela valorização dos conhecimentos pedagógicos na formação inicial e continuada dos profissionais do magistério, tendo:

A docência como ação educativa e como processo pedagógico intencional e metódico, envolvendo conhecimentos específicos, interdisciplinares e pedagógicos, conceitos, princípios e objetivos da formação que se desenvolvem na socialização e construção de conhecimentos, no diálogo constante entre diferentes visões de mundo. (BRASIL, 2015, p.7).

Nessa perspectiva, concebendo a docência a partir de conhecimentos específicos, interdisciplinares e pedagógicos, há o entendimento de uma aproximação e ressignificação com o campo da didática, especialmente ao anunciar no Art $5^{\circ}$ que:

A formação de profissionais do magistério deve assegurar a base comum nacional, pautada pela concepção de educação como processo emancipatório e permanente, bem como pelo reconhecimento da especificidade do trabalho docente, que conduz à práxis como expressão da articulação entre teoria e prática e a exigência de que se leve em conta a realidade dos ambientes das instituições educativas da educação básica e da profissão. (BRASIL, 2015, p.6).

Compreendemos que as afirmações expressas na Resolução 02/2015 (BRASIL, 2015) destacam nuances de que a formação inicial não se limita aos conhecimentos específicos e às técnicas de ensino, materializam-se sob os conhecimentos pedagógicos e sob os conhecimentos específicos. Questão que vem gerando amplo debate, apontada em pesquisas no cenário nacional da formação de professores (GATTI, 2010). Nesse sentido, a resolução anuncia que deverá ser garantido "[...] ao longo do processo, efetiva e concomitante relação entre teoria e prática, ambas fornecendo elementos básicos para o desenvolvimento dos conhecimentos e habilidades necessários à docência" (BRASIL, 2015, p.11).

Oliveira (2011) corrobora com nossa análise e afirma que o campo da didática é responsável por essa reflexão, estabelece conexões entre o papel sociopolítico da educação, da escola e do ensino; a compreensão do processo de ensino e suas múltiplas determinações, instrumentalizando teórica e praticamente o futuro professor para identificar e resolver os problemas postos pela prática pedagógica. Portando, segundo Martins e Romanowski (2015, p.142), a didática situa-se "[...] no eixo central das relações sociais e a base epistemológica compreende a teoria como expressão da prática, resultante de uma relação que é ao mesmo tempo material e social".

Concebemos, assim, como campo da didática, o estudo indissociável da didática geral, responsável pela formação política, sociológica e técnica do futuro professor e a didática específica, a compreensão do conteúdo ensinado e, ao mesmo tempo, ao conhecimento pedagógico do conteúdo. Juntos buscam uma aproximação com o ensino, a partir da unidade entre o conhecimento da disciplina e o conhecimento do ensino dessa disciplina, na compreensão do conteúdo e na articulação desse com a vida cotidiana (ROMANOWSKI, 2016). Brzezinski (2002) corrobora com essa perspectiva, afirmando que a profissionalização docente se constrói num conjunto de saberes e capacidades marcado por contínuas mudanças entre as teorias, processos pedagógicos e com a práxis educativa.

Ao apresentarmos o campo da Didática, compreendemos que seu objeto de estudo é o processo de ensino e aprendizagem, em suas múltiplas determinações, a partir da relação professor- 
estudante, o método de trabalho, a indissociabilidade entre teoria e prática, o planejamento, os objetivos, a prática avaliativa, os aspectos sociopolíticos da educação e as dimensões teóricas, técnicas e humanas (LIBÂNEO, 2013; MARTINS, 2012; OLIVEIRA, 2011; VEIGA, 1994).

Acerca dessa ressignificação ao campo da Didática, Shulman (apud GAIA, 2005, p. 54) destaca que o estudo a partir da didática específica e a didática geral contribui para que o bom ensino recaia "[...] sobre a capacidade dos professores em conhecer profundamente o que está ensinando (conteúdo específico) [...]" a partir de ações que sejam "[...] pedagogicamente eficazes, tendo em vista os propósitos de ensino". Assim, os professores estabelecem relações entre o conhecimento do conteúdo e o ensino desses mesmos conteúdos, imersos na realidade vivenciada a partir da aproximação entre a universidade e o chão da escola. Nessa perspectiva, há uma dupla aproximação a partir da questão anunciada na Resolução 02/2015, entre as disciplinas de didática geral e específica e ambas as escolas de educação básica.

Acerca ainda dessa aproximação, a Resolução 02/2015 (BRASIL, 2015) prevê uma formação por meio de

[...] uma sólida base teórica e interdisciplinar que reflita a especificidade da formação docente, assegurando organicidade ao trabalho das diferentes unidades que concorrem para essa formação; a inserção dos estudantes de licenciatura nas instituições de educação básica da rede pública de ensino, espaço privilegiado da práxis docente. (BRASIL, 2015, p.2).

Corroborando com as contribuições de Martins (2009, p. 18) ao ensino por meio da práxis e de uma didática crítica, próxima ao chão da escola, ao afirmar que esse caminho aponta para uma:

[...] forma para desenvolver um ensino de didática mais articulado com a realidade das escolas onde os futuros professores vão atuar. E mais: a prática tem me possibilitado preparar o futuro professor teórica e praticamente para explicar, compreender e intervir na prática pedagógica numa ação comprometida com as classes trabalhadoras.

Essa concepção beneficia, especialmente, a formação para os cursos destinados aos anos finais e ensino médio, uma vez que contemplam uma " [...] sólida formação teórica e interdisciplinar dos profissionais; inserção dos estudantes de licenciatura nas instituições de educação básica da rede pública de ensino, espaço privilegiado da práxis docente [...]" (DOURADO, 2015, p.8). Nesse sentido, a Resolução 02/2015 prevê a garantia de "[...] efetiva e concomitante relação entre teoria e prática, ambas fornecendo elementos básicos para o desenvolvimento dos conhecimentos e habilidades necessários à docência" (BRASIL, 2015, p.11).

Para atender a essas concepções e mudanças nas práticas formativas no ensino superior, Dourado (2015, p.10) explicita a necessidade de alterações nos projetos de formação, " [...] em consonância com o Plano de Desenvolvimento Institucional (PDI), o Projeto Pedagógico Institucional (PPI) e o Projeto Pedagógico de Curso (PPC)".

Frente a essa realidade e, atualmente, com as DCNs (BRASIL, 2015), é o momento de estabelecermos ações e repensarmos o currículo de formação de cursos de licenciatura, buscando a articulação da teoria, especialmente, a partir do estudo dos conhecimentos pedagógicos decorrentes do campo da Didática em todos os cursos de formação inicial de professores. Segundo Cunha (2015, p. 89), o currículo assentado nessa perspectiva exige:

Uma intensa relação entre prática e teoria, invertendo a lógica tradicionalmente posta pela modernidade. Neste 
caso, a prática se torna a base da reconstrução histórica, dando sentido ao estudo e aprofundamento de seus pressupostos. A teoria também se distancia das metanarrativas generalistas e inquestionáveis. Antes, se constitui em construtos que podem orientar a compreensão da prática, num processo intermediado por interpretações subjetivas e culturais que ressignifiquem a teoria para contextos específicos. Todos os docentes pertencentes ao programa de formação de professores têm de se envolver com o eixo da proposta curricular. Os conteúdos das diferentes disciplinas e áreas precisam ter a docência como referente e a realidade escolar como estruturante [...].

Permanece o desafio de inserir o campo da Didática, especialmente, o ensino da Didática Geral, a partir das DCNs (BRASIL, 2015), em todos os cursos de licenciatura, sob uma formação crítica, que transcenda a sala de aula e, finalmente, contemple as discussões desse campo, já aprofundadas desde a década de 1980.

\section{CONSIDERAÇÕES FinAis}

A formação de professores, conforme observamos no decorrer da pesquisa, denota uma formação que serve à sociedade definida pelo capital, determinada pela influência dos organismos internacionais e de uma política que valoriza o mercado e a competitividade. Reconhecemos, também, que a contradição aparece e se impõe na constituição das políticas, fato que pode colaborar com a resistência, os avanços e mesmo os retrocessos.

A trajetória apresentada permite afirmar que as políticas são impostas aos setores populares e esses não têm conseguido ser sujeitos das políticas, ainda que da luta do movimento docente brasileiro, aspecto que favorece a imposição das políticas educacionais, tanto na forma como no conteúdo, fortalecendo o esvaziamento da democracia na formulação e no acompanhamento da política pública; a retirada do Estado como sujeito da política pública estatal; ampliação do mercado público-privado; a fragilização da profissão docente na sociedade contemporânea, entre outros.

Articulado aos aspectos tratados, destacamos a prevalência nesse cenário de políticas educacionais que servem ao capital, adentram a formação inicial de professores e ecoam uma formação aligeirada; relativização do conhecimento científico e da formação densa do professor; aprofunda a desvalorização da escola, do magistério e da docência. Esse esvaziamento teórico de conteúdos reflexivos, científicos e políticos, recai nas escolas de educação básica, sob a aprovação da reforma do ensino médio, juntamente com a BNCC.

Podemos considerar que o pensamento e a concepção de formação de professores mantêm-se com rupturas e continuidades, sem transformações significativas ao longo de todo processo de constituição da educação brasileira. Instruir os cidadãos a servir; dividir cada vez mais a sociedade em classes; expandir cada vez mais o privado sob o público; formar um professor para reproduzir os manuais, tirando-Ihe a capacidade político-criativa. Na atualidade, estão instaurados de modo explícito por parte dos governos e um número significativo da população o enfrentamento e o desmonte do trabalho docente, aspectos esses que desvelam a realidade nas relações entre educação e sociedade.

Consideramos que a investigação desenvolvida permitiu compreender a Didática como uma área de formação humana que vem sofrendo alterações ao longo da história na política educacional, nas pesquisas acadêmicas e na formulação no campo escolar. O desafio está na aproximação desses campos na perspectiva do fortalecimento da didática na formação inicial dos professores. 
Acreditamos que o campo da didática é indispensável à formação inicial de professores, sobretudo, a partir da necessidade de ensinar as origens, a história e a epistemologia das diferentes áreas de formação. Cada disciplina escolar tem sua didática própria, metodologias específicas e essenciais a cada área e, juntamente com a Didática Geral, propiciam a formação didático pedagógica dos futuros professores, superando a premissa de solucionar o divórcio entre as necessidades atuais da escola de educação básica e a formação promovida nos âmbitos do ensino superior.

\section{REFERÊNCIAS}

BRZEZINSKI, I. Profissão professor: identidade e profissionalização docente. São Paulo: Parábola, 2002.

BRASIL. Conselho Nacional de Educação. Define as Diretrizes Curriculares Nacionais para a formação inicial em nível superior (cursos de licenciatura, cursos de formação pedagógica para graduados e cursos de segunda licenciatura) e para a formação continuada. Resolução CNE/CP n. 02/2015, de $1^{\circ}$ de julho de 2015. Brasília, Diário Oficial [da] República Federativa do Brasil, seção 1, n. 124, p. 8-12, 02 de julho de 2015.

Lei $n^{\circ}$ 9.394, de 20 de dezembro de 1996. Estabelece as diretrizes e bases da educação nacional. Diário Oficial da União, Brasília, DF, 23 dez. 1996.

Medida provisória no 746, de 22 de setembro de 2016. Disponível em: <http://www. planalto.gov.br/ccivil_03/_ato2015-2018/2016/Mpv/mpv746.htm>. Acesso em: 04 abr. 2017.

Resolução CNE/CP n ${ }^{\mathbf{1}}$, de 18 de fevereiro de 2002. Institui Diretrizes Curriculares Nacionais para a Formação de Professores da Educação Básica, em nível superior, curso de licenciatura, de graduação plena. Disponível em: http://portal.mec.gov.br/cne/arquivos/pdf/rcp01_02.pdf. Acesso em: 18 set. 2017.

CHAUÍ, M. Introdução à história da filosofia: dos pré-socráticos a Aristóteles. São Paulo: Brasiliense, 1994.

CUNHA, M. I. Formação de professores: espaços e processos em tensão. In: SILVA JUNIOR, C. A. da; GATTI, B. A.; MIZUKAMI, M. G. N.; PAGOTTOo, M. D. S.; SPAZZIANI, M. L. (Orgs.). Por uma revolução no campo da formação de professores. 1.ed. São Paulo: Editora Unesp, 2015.

DOURADO, L. F. Diretrizes Curriculares Nacionais para a Formação Inicial e Continuada dos Profissionais do Magistério da Educação Básica: concepções e desafios. Educação e Sociedade, Campinas, SP, v. 36, n. 131, p. 299-324, 2015. Disponível em: http://www.scielo.br/pdf/es/v36n131/1678-4626-es-36131-00299.pdf Acesso em: 12 set. de 2016.

DUARTE, N. (Org.). Crítica ao fetichismo da individualidade. Campinas: Autores Associados, 2004.

EVANGELISTA, O.; MORAES, M. C.; SHIROMA, E. O. Política educacional. Rio de Janeiro: Lamparina, 2007.

FREITAS, L. C. Crítica da organização do trabalho pedagógico e da didática. 5. ed., Campinas: Papirus, 1995.

A reforma do ensino superior no campo da formação dos profissionais da educação básica: as políticas educacionais e o movimento dos educadores. Educação e Sociedade, Ano XX, n.68, p.17-44, dez. 1999.

Ensino Médio: modelo subserviente para um país dependente. Disponível em: https:// 
avaliacaoeducacional.wordpress.com/2016/09/24/ensino-medio-modelo-subserviente-paraumpais-dependente/?iframe=true\&theme_preview=true Acesso em 17 set 2017.

FRIGOTO, G. Educação omnilateral. In: CALDART, R. S. et al. Dicionário da educação do campo. Rio de Janeiro: Escola Politécnica de Saúde Joaquim Venâncio; São Paulo: Expressão Popular, 2012. p. $265-272$.

Escola sem partido: imposição da mordaça aos educadores. Disponível em: <https:// avaliacaoeducacional.com/2016/06/27/frigotto-critica-da-escola-sem-partido/>. Acesso em 24 set. 2017.

GAIA, S. O professor e a base do conhecimento. In: RIBAS, M. H. (Org.). Formação de professores: escolas, práticas e saberes. Ponta Grossa: EdUEPG, 2005.

GATTI, B. A. Professores do Brasil: impasses e desafios. Brasília: UNESCO, 2009.

Formação de professores no Brasil: características e problemas. Educação e Sociedade, Campinas, v. 31, n. 113, p. 1355-1379, out.-dez. 2010. Disponível em http://www.cedes.unicamp.br. Acesso em 07 set. 2017.

GHEDIN, E. Educação do campo: epistemologia e práticas. 1. ed. São Paulo: Cortez, 2012.

LEHER, R. Um novo senhor da educação? A política educacional do Banco Mundial para a periferia do capitalismo. In: São Paulo: Instituto de Estudos Sociais, Outubro, n 3. 1999. p. 19-30.

LIBÂNEO, J. C. Democratização da Escola Pública e Pedagogia Crítica Social dos Conteúdos. 15. ed. São Paulo: Loyola, 1985.

Democratização da escola pública. São Paulo: Loyola, 1991.

Didática. 28. ed. São Paulo: Cortez, 2008;2013.

Didática: velhos e novos temas. Edição do Autor, 2002. Disponível em http://nead.uesc. br/arquivos/Biologia/scorm/Jose_Carlos_Libaneo-Livro_Didatica_Lib_oneo_pdf. Acesso em: 21 set.2017.

LIMA, M. F. et al. A função do currículo no contexto escolar. Curitiba: Intersaberes, 2012.

LÜDKE, M.; ANDRÉ, M. E. D. A. Pesquisa em Educação: Abordagens Qualitativas. São Paulo: EPU, 1986.

MARCELO, C. Formação de professores: para uma mudança educativa. Porto: Porto Editora, 1999.

MARIN, A. J.; PIMENTA, S. G. Didática: teoria e pesquisa. Araraquara, SP: Junqueira \& Martin, 2015.

MARTINS, P. L. A Didática e as contradições da prática. 3. ed. Campinas, SP: Papirus, 2009.

As formas e práticas de interação entre professores e estudantes. In: VEIGA, I. P.A (Org.).

Lições de didática. Campinas: Papirus, 2012.

MARTINS, P. L.; ROMANOWSKI, J. P. Formação didática dos professores a partir da sistematização coletiva do conhecimento. In: MIGUEL, M.; FERREIRA, J. L. (Orgs.). Formação de Professores: História, Políticas Educacionais e Práticas Pedagógicas. Curitiba: Ed. Apriss, 2015.

MELO, A. de; URBANETZ, S. T. Fundamentos da didática. Curitiba: IBPEX, 2008.

OLIVEIRA, M. R. A pesquisa em Didática no Brasil: da tecnologia à teoria pedagógica. In: PIMENTA, S. G. (Org.). Didática e formação de professores: percursos e perspectivas no Brasil e em Portugal.

6. ed. São Paulo: Cortez, 2011. 
A reconstrução da didática: elementos teórico-metodológicos. Campinas: Papirus, 1992.

PIMENTA, S. G. O estágio na formação de professores: unidade teoria e prática? 11. ed. São Paulo: Cortez, 2012.

ROMANOWSKI, J. P. Conhecimentos pedagógicos nos cursos de licenciatura e a base comum de formação de professores. In.: CARTAXO, S. R. M.; MARTINS, P. L. O.; ROMANOWSKI, J. P. Práticas formativas de formação de professores: da educação básica à educação superior. Curitiba: PUCPress, 2016.

Formação e profissionalização docente. 3. ed. Curitiba: IBPEX, 2007.

ROMANOWSKI, J. P.; GISI, M. L.; MARTINS, P. L. FÓRUNS DE LCENCIATURA: que contribuições para a formação de professores? Revista Diálogo Educacional, Curitiba, v. 8, n. 23, p. 121-135, jan./abr. 2008.

SAVIANI, D. A Pedagogia no Brasil: história e teoria. Campinas: Autores Associados, 2008.

Escola e democracia: teorias da educação, curvatura da vara, onze teses sobre a educação política. Campinas: Autores Associados, 1983, 1991, 2009.

Ensino público e algumas falas sobre a universidade. São Paulo: Cortez, Autores Associados, 1984.

O conceito dialético de mediação na Pedagogia Histórico-Crítica em intermediação com a Psicologia Histórico-Cultural. Marxismo e Educação em Debate. Salvador, v. 7, n. 1, p. 26-43, jun. 2015. Disponível em file:///C:/Users/Juliana/Downloads/12463-42108-1-PB.pdf acesso em 07 set 2017.

SCHEIBE, L.; BAZZO, V. L. Diretrizes Curriculares Nacionais para os Cursos de Licenciatura no Brasil: da regulamentação aos Projetos Institucionais. Educação em Perspectiva, Viçosa, MG, v. 4, n. 1, p. 15-36, jan./jun. 2013.

TONET, I. Educação contra o capital. São Paulo. Instituto Luckács. Edição Ampliada, 2016.

UNESCO. Declaração mundial sobre educação para todos (Conferência de Jomtien). Tailândia: Unesco, 1990. Disponível em: http://unesdoc.unesco.org/images/0008/ 000862/086291por.pdf . Acesso em: 10 set de 2017.

VEIGA, I. P. A. A prática pedagógica do professor de didática. 2. ed. Campinas: Papirus, 1994. (Coord). Repensando a Didática. Campinas, São Paulo: Papirus, 2012.

VILLAS, Carlos. O Banco Mundial e a reforma do estado na América Latina: fundamentos teóricos e prescrições políticas. In: PEREIRA, J. M. M. (Org.). A demolição de direitos: um exame das políticas do Banco Mundial para a educação e a saúde (1980-2013). Rio de Janeiro: Escola Politécnica de Saúde Joaquim Venâncio, 2014.

Artigo recebido em: 09/10/2017 Aprovado em: 19/01/2018

Contato para correspondência: Marcos Gehrke. E-mail: marcosgehrke@gmail.com 